\title{
Association of azoospermia factor region deletions in infertile male subjects among Malaysians
}

\begin{abstract}
Azoospermia factor region (AZF) deletions (AZFa, AZFb, AZFc and AZFd) in the $\mathrm{Y}$ chromosome were analysed in male infertility subjects in various populations with conflicting results. This study comprised of 54 infertile males and 63 fertile controls, and the frequency of $\mathrm{AZFa}, \mathrm{AZFb}, \mathrm{AZFc}$ and $\mathrm{AZFd}$ deletions were determined using conventional polymerase chain reaction (PCR) as well as real-time PCR-high resolution melting analysis-based methods. The results of this study showed that, three of 54 cases $(5.55 \%)$ had AZF (a, b and c) deletions (two had AZFc and one had AZFa deletions). Four cases were found to have AZFd deletions $(7.4 \%)$ with two of them being associated with AZFc deletions $(\mathrm{P}=0.028)$. The frequency of AZF ( $a, b$ and $c$ ) deletions in Malaysian infertile male subjects was found to be comparable with other populations. AZFd deletions were found to be significant $(\mathrm{P}<$ 0.05) in male infertility and it may be associated with other types of AZF deletions.
\end{abstract}

Keyword: Azoospermia factor region; High resolution melt; Male infertility 